\title{
Antibody Disulfide Bond Reduction and Recovery during Biopharmaceutical Process Development - A Review
}

\author{
Tingwei Ren ${ }^{1}$, Zhijun Tan ${ }^{1}$, Vivekh Ehamparanathan ${ }^{2}$, Angela Lewandowski ${ }^{1}$, Sanchayita \\ Ghose $^{1}$, and Zheng Jian $\mathrm{Li}^{3}$ \\ ${ }^{1}$ Bristol Myers Squibb \\ ${ }^{2}$ Bristol-Myers Squibb Co \\ ${ }^{3}$ Bristol-Myers Squibb Company
}

December 19, 2020

\begin{abstract}
Disulfide bond reduction has been a challenging issue in antibody manufacturing, as it leads to reduced product purity, failed product specifications and more importantly, impacting drug safety and efficacy. Scientists across industry have been examining the root causes and developing mitigation strategies to address the challenge. In recent years, with the development of hightiter mammalian cell culture processes to meet the rapidly growing demand for antibody biopharmaceuticals, disulfide bond reduction has been observed more frequently. Thus, it is necessary to continue evolving the disulfide reduction mitigation strategy and development of novel approaches to achieve high product quality. Additionally, in recent years as more complex molecules emerge such as bispecific and trispecific antibodies, the molecular heterogeneity due to incomplete formation of the interchain disulfide bonds becomes a more imperative issue. Given the disulfide reduction challenges that our industry are facing, in this review, we provide a comprehensive contemporary scientific insight into the root cause analysis of disulfide reduction during process development of antibody therapeutics, mitigation strategies and recovery based on our expertise in commercial and clinical manufacturing of biologics. First, this paper intended to highlight different aspects of the root cause for disulfide reduction. Secondly, to provide a broader understanding of the disulfide bond reduction in downstream process, this paper discussed disulfide bond reduction impact to product stability and process performance, analytical methods for detection and characterization, process control strategies and their manufacturing implementation. In addition, brief perspectives on development of future mitigation strategies will also be reviewed, including platform alignment, mitigation strategy application for bi- and tri-specific antibodies and using machine learning to identify molecule susceptibility of disulfide bond reduction. The data in this review are originated from both the published papers and our internal development work.
\end{abstract}

\section{Antibody Disulfide Bond Reduction and Recovery during Biopharmaceutical Process Devel- opment - A Review}

Tingwei Ren, Zhijun Tan, Vivekh Ehamparanathan, Angela Lewandowski, Sanchayita Ghose, Zheng Jian Li

Biologics Development, Global Product Development and Supply, Bristol-Myers Squibb, Devens, MA

\section{Correspondence}

Zhijun Tan, Biologics Development, Global Product Development and Supply, Bristol-Myers Squibb, 38 Jackson Road, Devens, MA 01434.

Email: zhijun.tan@bms.com

\section{Abstract}


Disulfide bond reduction has been a challenging issue in antibody manufacturing, as it leads to reduced product purity, failed to meet targeted product profile and/or specifications and more importantly, impacting drug safety and efficacy. Scientists across industry have been examining the root causes and developing mitigation strategies to address the challenge. In recent years, with the development of high-titer mammalian cell culture processes to meet the rapidly growing demand for antibody biopharmaceuticals, disulfide bond reduction has been observed more frequently. Thus, it is necessary to continue evolving the disulfide reduction mitigation strategy and development of novel approaches to maintain high product quality. Additionally, in recent years as more complex molecules emerge such as bispecific and trispecific antibodies, the molecular heterogeneity due to incomplete formation of the interchain disulfide bonds becomes a more imperative challenging issue. Given the disulfide reduction challenges that biotech industry is facing, in this review we provide a comprehensive contemporary scientific insight into the root cause analysis of disulfide reduction during process development of antibody therapeutics, mitigation strategies and its potential remediated recovery based on our expertise in clinical and commercial manufacturing of biologics. First, this paper intended to highlight different aspects of the root cause for disulfide reduction. Secondly, to provide a broader understanding of the disulfide bond reduction in downstream process, this paper discussed disulfide bond reduction impact to product stability and process performance, associated analytical methods for detection and characterization, process control strategies as well as their manufacturing implementation. In addition, brief perspectives on development of future mitigation strategies will also be reviewed, including platform alignment, mitigation strategy application for the emerging new modalities such as biand tri-specific antibodies as well as using machine learning to identify molecule susceptibility of disulfide bond reduction. The data in this review are originated from both the published papers and our internal development work.

\section{KEYWORDS}

Antibody, Disulfide bond, Reduction/Oxidation, Process development

\section{INTRODUCTION}

Antibodies are proteins produced by immune cells and help to defend the host when facing foreign invaders (Dowd, Halonen, \& Maier, 2009). Monoclonal antibodies (mAbs) are antibodies with single specificity generated from plasma B cells in vitro (Nelson et al., 2000). Compared with small chemical molecules, mAbs showed advantages such as high selectivity and potency, which improve therapeutic efficiency and reduce the toxicity (Cui, Cui, Chen, Li, \& Guan, 2017; Imai \& Takaoka, 2006). Due to these advantages, commercial mAbs have been developed rapidly since U.S Food and Drug Administration (FDA) approved the first mAb product in 1986 (Ecker, Jones, \& Levine, 2015). Based on Nature Reviews Drug Discovery reports (Hughes, 2010; Mullard, 2011, 2012, 2013, 2014, 2015, 2016, 2017, 2018, 2019, 2020), in the last ten years (2009 - 2019), 61 out of 95 FDA approved Biologics License Applications (BLAs) were mAb products or $\mathrm{mAb}$ related products, and the percentage of $\mathrm{mAb}$ (or $\mathrm{mAb}$ related) products in the BLAs increased over time (Figure S1).

Commercial mAbs are generally produced in mammalian cells such as Chinese hamster ovary (CHO) (Du et al., 2018; Kao, Hewitt, Trexler-Schmidt, \& Laird, 2010; T. Wang, Liu, Cai, Huang, \& Flynn, 2015). Ideally, the disulfide bonds of antibody should pair correctly before mAbs are secreted extracellularly. Correct disulfide bonds pairings are critical during the mAb development process: (1) to meet ICH Q6B specifications for biotechnological and biological products that the number and the position of disulfide bridges should be determined based on the gene sequence for the desired product (Lakbub, Shipman, \& Desaire, 2018); (2) to ensure antibody drug therapy efficiency and eliminate the immunogenicity (Kao et al., 2010; Swope et al., 2020). It is also critically important for bi- and tri- specific antibody (BsAb and TsAb) stability improvement during the drug product development (Caravella \& Lugovskoy, 2010; Rossi et al., 2006; Vaks, 2018). Many research studies have been conducted to analyze and understand the function of disulfide bond structure on antibody stability, and there are several reviews on this topic (Correia, 2010; H. Liu \& May, 2012; Trivedi, Laurence, \& Siahaan, 2009b). While developing the fundamental understanding of disulfide bond structure and function, great research efforts have been made to identify the root cause of disulfide bond reduction 
happened during mAb manufacturing process, and develop measures to minimize the reduction as well as to recover the reduced $\mathrm{mAb}$ during the downstream process (Du et al., 2018; Hutterer et al., 2013; Kao et al., 2010; Mun et al., 2015; Tan et al., 2020; Tang et al., 2020; Trexler-Schmidt et al., 2010). As far as the authors are aware of, most of these studies focused on certain downstream process steps instead of the whole downstream process, with relatively limited discussions on the effect of disulfide bond reduction on downstream processing. In reality, it is rather challenging to completely eliminate disulfide bond reduction in a single downstream process step. Therefore, to minimize disulfide bond reduction, understanding how to apply the mitigation strategies across multiple downstream process steps is necessary.

To accommodate the aforementioned need, this paper first reviews the root causes of disulfide bond reduction, and then discusses how existing mitigation strategies have been able to address this issue. By summarizing these mitigation strategies, we are able to provide a work chart to bridge disulfide bond reduction mitigation strategies during $\mathrm{mAb}$ downstream processing. A case study will then be presented as an example to illustrate how these approaches were applied to downstream manufacturing process. In addition, this paper also discusses the effects of disulfide bond reduction on downstream process, and the associated analytical methods for disulfide bond analysis, and future perspectives, based on our own experiences, in addressing the disulfide bond reduction challenges for mAbs and multi-specific antibodies, all of which provide a broader view of disulfide bond reduction challenge in mAbs and multi-specific antibodies downstream processing. This article provides a useful resource for people in biotech industry who are facing the challenge of disulfide bond reduction during the antibody process development.

\section{DISULFIDE BONDS in Therapeutica Proteins}

\subsection{Disulfide bond structure in mAbs}

A major advancement in antibody structure was revealed in the 1960s by Gerald M. Edelman and Rodney R. Porter, who were awarded 1970 Nobel Prize "for their discoveries concerning the chemical structure of antibodies" (Edelman \& Gall, 1969; Edelman \& Gally, 1962; Preud'homme, Petit, Barra, Morel, \& Lelièvre, 2000; Raju, 1999). There are five subclasses of antibodies (immunoglobulins): IgA, IgD, IgE, IgG and IgM. Each subclass of antibodies are composed of one or several immunoglobulin (Ig) monomers. An Ig monomer has two identical heavy chains and two identical light chains. Figure 1A and 1B showed an example of the disulfide bonds presented in IgG monomers (Correia, 2010; H. Liu \& May, 2012). Both heavy chains and light chains are composed of constant domain and variable domains, which are constructed from two betasheets $(\beta$-sheets). Disulfide bonds that connect the two $\beta$-sheets in a single domain are known as intra-chain disulfide bonds (Figure 1A)(W. Li et al., 2016). Disulfide bonds that connect two heavy chains or connect a light chain and a heavy chain are known as inter-chain disulfide bonds. In an IgG monomer (Figure 1B), there are twelve intra-chain disulfide bonds (one per domain), two inter-chain disulfide bonds between light chain and heavy chain, and two to eleven inter-chain disulfide bonds between two heavy chains. Researchers found that inter-chain disulfide bonds are more prone to degrade than intra-chain disulfide bonds (Kikuchi, Goto, \& Hamaguchi, 1986; H. Liu, Chumsae, Gaza-Bulseco, Hurkmans, \& Radziejewski, 2010). There are two possible reasons for the higher stability of intra-chain disulfide bond: (1) as shown in Figure 1A, intrachain disulfide bond are buried inside the two $\beta$-sheets (Amzel \& Poljak, 1979) and the accessible area of intra-chain disulfide bonds have been calculated to be zero (Kikuchi et al., 1986); (2) Molecule Dynamic (MD) simulation found that the atom distance of sulfur molecules for intra-chain disulfide bond is shorter than that for inter-chain disulfide bond, which may benefit the intra-chain disulfide bond higher stability than inter-chain disulfide bond (X. Wang, Kumar, \& Singh, 2011).

\subsection{Disulfide bond structure in BsAbs and TsAbs}

BsAbs and TsAbs (also known as multi-specific antibodies) are artificially designed complex antibodies that are capable of binding two or more antigens (Brinkmann \& Kontermann, 2017; Kontermann \& Brinkmann, 2015; Runcie, Budman, John, \& Seetharamu, 2018; Sedykh, Prinz, Buneva, \& Nevinsky, 2018). They are thought to have improved therapy efficiency since they have the ability to bind to two or more different targets simultaneously (Runcie et al., 2018; Tustian, Endicott, Adams, Mattila, \& Bak, 2016; Wu et al., 2020). Due 
to this advantage, multi-specific antibodies development has gained increasing attention in recent years. By 2019, there are more than 110 BsAbs reported under clinical development (Nie et al., 2020).

Disulfide bond structures also exist in BsAbs and TsAbs. Since there are more existing studies on BsAbs than TsAbs, here we use BsAbs as examples to illustrate disulfide bond function in multi-specific antibodies. Besides the similar functions that disulfide bonds exhibit in $\mathrm{mAbs}$, disulfide bonds play a critical role in avoiding BsAb chain mispairing and keeping BsAb structure stable. Figures 1C-1E show three examples that illustrated disulfide bonds roles in two subclasses of BsAbs, immunoglobulin G (IgG)-like BsAb (having an Fc region, Figure 1C and Figure 1D) and small BsAb (lacking an Fc region, Figure 1E)(Elgundi, Reslan, Cruz, Sifniotis, \& Kayser, 2017; Kontermann \& Brinkmann, 2015).

First example shows how the disulfide bonds improve the stability of KIH IgG-like BsAb (Figure 1C). In an IgG-like BsAb design, one way to correctly pair the heavy chains from different antibodies is the "Knobsinto-holes" (KIH) approach: in one heavy chain where a small amino acid in the CH3 domain is replaced by a large amino acid (functioned as "knobs") and in the other heavy chain where a large amino acid is replaced by a small amino acid (functioned as "holes")(Brinkmann \& Kontermann, 2017). The stability of this heterodimeric region is further improved by forming additional disulfide bonds in this region. Some research reported that inducing the disulfide bond to the KIH design can improve functional BsAb yield by $10 \%$, and overall higher than 90\% functional BsAb yield (Carter, 2001; Klein et al., 2012).

In the second example, disulfide bonds improve the rate and efficiency of correctly pairing heavy chain with light chain in IgG-like BsAb (Figure 1D). Besides forming heterodimeric heavy chain pair, two light chains also need to correctly pair with the corresponding heavy chains. One way to improve the correct light chainheavy chain pairing is to introduce an artificial disulfide bond in one arm. Researchers mutated the pair of cysteines, forming a disulfide bond between heavy chain and light chain constant regions, to valines, and introduced a new pair of cysteines in different location in heavy chain and light chain constant regions to form an engineered disulfide bond. In this way, the mutated light chain can only pair with the mutated heavy chain and vice versa, the un-mutated light chain can only pair with the un-mutated heavy chain (Mazor et al., 2015).

Last example illustrates the disulfide bonds link the two heavy chain variable region in Dual-affinity Retargeting (DART) small BsAb design (Figure 1E). DART BsAb is another type of the BsAb designs (Nie et al., 2020). As shown in Figure 1E, in DART design, light chain variable region from one antibody was

linked with heavy chain variable region from the other antibody by small peptide, and the two heavy chain variable regions were linked by disulfide bond. The short linker sizes of DART design can improve small BsAb stability and reduce immunogenicity (Johnson et al., 2010).

\section{IMPACT OF DISULFIDE REDUCTION ON DOWNSTREAM PROCESSING}

As discussed above, correct disulfide bond formation is required for proper antibody folding and maintaining their bioactivity and stability (Lakbub et al., 2016). Researchers found that the unpaired free thiols could form incorrect disulfide bonds and result in covalent aggregation (Andya, Hsu, \& Shire, 2015; Cromwell, Hilario, \& Jacobson, 2006; Vázquez-Rey \& Lang, 2011; W. Zhang \& Czupryn, 2002). Protein aggregates in the final drug products could induce adverse immune responses in patients and cause immunogenicity (Moussa et al., 2016). The mechanisms of how protein aggregations cause immunogenicity is a separate but interesting research topic (Bessa et al., 2015; Moussa et al., 2016; Ratanji, Derrick, Dearman, \& Kimber, 2014; Rosenberg, 2006) and out of the scope of this paper. Instead, to the best of our knowledge, there are limited studies reporting disulfide bond reduction impact on whole downstream processing performance. As such, this section we discuss disulfide bond reduction impact on downstream processing, including the challenge of identifying reduced mAbs and disulfide bond reduction effects on mAbs stability based on our own commercial antibody process development experiences.

\subsection{Identification of reduced $\mathrm{mAb}$ during the downstream processing}

Besides the incorrect disulfide bond formation, the unpaired free thiols may change the antibody's surface 
charge distribution and hydrophobicity, which consequently will result in different chromatographic profiles during $\mathrm{mAb}$ process development. For example, in cation exchange chromatography - high performance liquid chromatography (CEX-HPLC) and anion exchange chromatography (AEX-HPLC) analysis, mAbs with and without free thiols showed separate peaks at different elution times (Chen, Nguyen, Jacobson, \& Ouyang, 2009; Cheng et al., 2017; Pristatsky et al., 2009; T. Zhang et al., 2012). However, to the best of our knowledge, there are very few papers that reported the effects of disulfide bond reduction on the performance of the downstream processing, particularly whether the disulfide reduced $\mathrm{mAbs}$ can be identified during downstream processing. Here, we use three monoclonal antibodies (mAb1 (IgG1, pI 8.2), mAb2 (IgG4, pI 8.0), mAb3 (IgG4, pI 6.8)) purified in our in-house studies as examples to show the impact of disulfide bond reduction on individual downstream purification processes, including Protein A chromatography, low $\mathrm{pH}$ viral inactivation (VI) and ion exchange chromatography (IEX) respectively.

(1) Protein A chromatography . For Protein A chromatography separation, the affinity between mAb and Protein A ligand is primarily through the Fc region of the antibody. Since the high-order structure of the disulfide-reduced $\mathrm{mAb}$ is intact, the affinity between reduced $\mathrm{mAb}$ and Protein $\mathrm{A}$ resin would remain unchanged (Tan et al., 2020). As presented in Figure 2A, the Protein A chromatography profile of the low level disulfide reduced $\mathrm{mAb} 3$ sample (containing $89.5 \%$ intact $\mathrm{mAb} 3$ ) and the high level disulfide reduced $\mathrm{mAb} 3$ sample (containing $10.6 \%$ intact $\mathrm{mAb} 3$ ) were identical. Additionally, no noticeable process yield difference was observed between the reduced $\mathrm{mAb}$ and intact $\mathrm{mAb}$ on Protein A chromatography step. These results confirmed that disulfide reduction had no major impact on the Protein A chromatography step.

(2) Low pH viral inactivation (VI) . A previous study showed that high level of disulfide bond reduction may increase the aggregation level after low pH viral inactivation (Chung et al., 2017). However, a clear trend was not observed for disulfide reduction effects on protein aggregation based on mAb1 and mAb2 low $\mathrm{pH}$ viral inactivation results. As shown in Figure 3A, after low $\mathrm{pH}$ viral inactivation the high molecular weight (HMW) level increased by $0.6 \%$ and $0.5 \%$ for intact $\mathrm{mAb} 1$ pool and reduced $\mathrm{mAb} 1$ pool, respectively. In contrast, the HMW level decreased by $1.7 \%$ for the intact mAb2 pool verses a decrease of $0.3 \%$ for the reduced $\mathrm{mAb} 2$ pool. The lack of consistent trend for disulfide reduction impacts on aggregation at the low pH VI step indicates that there may be other more critical contributing factors to the aggregation formation, such as intrinsic molecular properties (e.g. mAb type and hydrophobicity).

(3) IEX . As discussed above, disulfide reduction may change mAb surface charge distribution, which subsequently lead to the appearance of separate peaks in CEX-HPLC and AEX-HPLC analysis. Here, we compared AEX profiles and CEX profiles respectively for two runs of mAb1 with different levels of disulfide reduction (Figure $2 \mathrm{~B}$ and $2 \mathrm{C}$ ). AEX step of $\mathrm{mAb} 1$ was operated in flow through $(\mathrm{F} / \mathrm{T})$ mode, and the results in Figure 2B showed that the overall patterns of AEX are similar between the low level disulfide reduced $\mathrm{mAb}$ sample $(>95 \%$ intact $\mathrm{mAb})$ and the high level disulfide reduced $\mathrm{mAb}$ sample $(67 \%$ intact $\mathrm{mAb})$. The differences in the $\mathrm{F} / \mathrm{T}$ volumes during the loading step were due to differences in the initial loading sample volumes. Similarly for CEX step (bind elute mode, performed after AEX), disulfide reduction level did not show significant impact on the overall CEX profile (Figure 2C). However, it was noticed that the mAb1 sample having had a high level of disulfide reduction showed longer peak tailing than the ones that had a low level of disulfide reduction at the end of the AEX loading step (Figure 2B) and at the end of the CEX elution step (Figure 2C), respectively. The differences in the peak tailing for both AEX $(\mathrm{F} / \mathrm{T}$ ) and CEX (B/E) could be due to the difference of disulfide reduction levels. However, it is not clear whether this type of chromatographic difference generally exists in all types of mAbs. In fact, the difference in the chromatographic profiles between the intact $\mathrm{mAb}$ and reduced $\mathrm{mAb}$ is so subtle that it would be very challenging to identify the highly reduced mAb just based on chromatography profiles alone. Thus, fast but accurate analytical methods should be used in the downstream purification process for disulfide bond reduction monitoring and determination. These methods will be discussed in more detail in Section 4.

Besides comparing intact $\mathrm{mAb}$ and highly reduced $\mathrm{mAb}$ profiles at different downstream process unit operation step, it was also noticed that for the highly reduced sample of $\mathrm{mAb} 1$ and $\mathrm{mAb} 2$, the purity increased from $64 \%$ and $35 \%$ in the Protein A chromatography pools to $94 \%$ and $92.9 \%$ in IEX pools respectively 
(Figure 3B). The increase of $\mathrm{mAb}$ purity during downstream purification process may be due to removal of reduced mAbs species during downstream purification, and/or reoxidation of reduced mAbs during downstream purification. To confirm this, we did conduct a study that used the disulfide re-oxidation strategy to recover the previously reduced $\mathrm{mAb}$ in downstream process (Tan et al., 2020; Tang et al., 2020).

\subsection{Disulfide bond reduction impact $\mathrm{mAb}$ stability in downstream processing}

Disulfide bonds enhance protein stability (Bulleid \& Ellgaard, 2011; Chung et al., 2017; Zhu, Dupureur, Zhang, \& Tsai, 1995). It is reasonable to expect that improper disulfide bond formation and disulfide bond reduction would impact process performance, protein stability and biological functionality. (Chung et al., 2017; Fass, 2012; H. Liu et al., 2014; Manteca et al., 2017; Trivedi, Laurence, \& Siahaan, 2009a; T. Wang et al., 2015). Disulfide reduction generates free sulfhydryl groups on the cysteine residue, potentially resulting in decreased thermal stability, $\mathrm{pH}$ stability, and potency as well as elevated aggregation (Harris, 2005; Huh, White, Brych, Franey, \& Matsumura, 2013; Lacy, Baker, \& Brigham-Burke, 2008). However, in our internal low $\mathrm{pH}$ viral inactivation (VI) study, we did not observe a general correlation between the aggregation level at the post-low pH VI step and the initial low molecular weight percentage resulting from disulfide bond reduction (as discussed in Section 3). It was suggested that the sensitivity of antibody aggregation to disulfide bond reduction may be dependent on the characteristics of the molecule (Manteca et al., 2017). In our study, we performed thermal and photostability studies using samples containing different levels of starting LMW species (resulting from disulfide reduction). As shown in Figure 4, light exposure led to significant increase of aggregate formation in comparison to the high temperature and room temperature exposures. Specifically, a higher aggregation rate was observed for the sample containing initial higher level of LMW species under the light exposure condition. In contrast, both initial high and low levels of LMW samples did not show significant difference of aggregation rate at room temperature. At high temperature $\left(40{ }^{\circ} \mathrm{C}\right)$, the overall aggregation levels trended higher over time and the initial LMW level also influenced the aggregate formation rate, but at a much slower rate compared to the light exposure condition. The significant impact of the LMW level on the sample photostability highlighted the importance of controlling the disulfide bond reduction in the manufacturing process.

\section{ROOT CAUSE ANALYSIS FOR DISULFIDE BOND REDUCTION}

MAb disulfide bond reduction is essentially an oxidation-reduction (redox) reaction that involves redox enzyme. Glutathione and thioredoxin system (comprising thioredoxin, thioredoxin reductase and nicotinamide adenine dinucleotide phosphate (NADPH)) are the known enzymes, and enzyme systems, that contribute to disulfide reduction (Chakravarthi \& Bulleid, 2004; Handlogten, Zhu, \& Ahuja, 2017; Koterba, Borgschulte, \& Laird, 2012; O'Mara et al., 2019). NADPH is generated from the pentose phosphate pathway and serves as an electron source in the disulfide bond reduction reaction (Arne Holmgren \& Lu, 2010). Electrons first transfer from NADPH to thioredoxin reductase (TrxR) and reduce the TrxR disulfide bond, then move to the oxidized thioredoxin ( $\operatorname{Tr} x)$ to form the reduced thioredoxin, and finally reduce the mAb disulfide bond. Glutathione (GSH) catalyzes the disulfide bond reduction in a similar way as Trx system (Gilbert, 1995; Handlogten et al., 2017; Meister \& Anderson, 1983) (Figure S2). Therefore, during manufacturing processing including both upstream and downstream, factors that promote these enzyme-catalyzed reactions can lead to disulfide bond reduction. With this root cause analysis, we categorized the factors that influence $\mathrm{mAb}$ disulfide bond reduction into the following types:

\subsection{Enzymatic factors.}

Researchers found that during the protein harvest operation, high mechanical shear force could cause cell lysis. Consequently, more intracellular enzymes are released to the Harvest Cell Culture Fluid (HCCF) thus lead to a higher level of disulfide bond reduction (Hutterer et al., 2013; Trexler-Schmidt et al., 2010). Alternatively, low dissolved oxygen (DO) levels in cell culture or HCCF can also cause disulfide bond reduction since there is a limited amount of oxygen molecules to consume NADPH, thus leaving enough NADPH as "electron fuel" for the disulfide bond reduction reaction (Mun et al., 2015; O'Mara et al., 2019). These aspects of root causes have been the focus of recent industrial studies. 


\subsection{Physical factors.}

Environment $\mathrm{pH}$ and temperature are two best known factors that influence enzyme reaction rate. As a consequence, $\mathrm{mAb}$ disulfide bond reduction level is higher when cell culture $\mathrm{pH}$ is closer to neutral $\mathrm{pH}$ since the NADPH oxidization rate was higher under a neutral $\mathrm{pH}$ condition $(\mathrm{pH}$ 7.0) than acidic $\mathrm{pH}$ condition (e.g. pH 6.5) (A. Holmgren, 1979; P. Xie et al., 2016). In addition, Low temperature could also slow the enzyme reaction rate and eventually reduced the disulfide bond reduction level (Hutterer et al., 2013; H. Liu, Nowak, Shao, Ponniah, \& Neill, 2016; O'Mara et al., 2019). Furthermore, short HCCF storage time can eliminate the disulfide bond reduction level as the reaction time was reduced (Mun et al., 2015; O'Mara et al., 2019). However, it should be noted that if the storage time is long enough, the reduced $\mathrm{mAb}$ can re-oxidize and form intact $\mathrm{mAb}$ in HCCF as the enzymes lose their activities (Mun et al., 2015).

\subsection{Intrinsic factors.}

While disulfide bond reduction is generally observed during the $\mathrm{mAb}$ manufacturing process, the reduction level depends on the mAb subclass and the light chain type (Hutterer et al., 2013). It was found that mAb disulfide bond susceptibility to enzymatic activity was as follows: $I g G 1 \lambda>I g G 1 \kappa>I g G 2 \lambda>I g G 2 k$, which could be related to differences in the NADPH availability with different cell lines and molecular structure differences (e.g. IgG2 is more compact than IgG1) (Magnusson, Björnstedt, \& Holmgren, 1997; Q. Zhang \& Flynn, 2013).

\section{ANALYTICAL METHODS FOR DISULFIDE BOND REDUCTION MONITORING AND ANALYSIS}

As discussed in Section 3, identifying potential disulfide reduction based on downstream processing unit operation profiles could be challenging, since highly reduced $\mathrm{mAb}$ samples and intact $\mathrm{mAb}$ samples showed similar peak profiles. In addition, protein properties can change drastically due to peptide bond cleavage (Magnusson et al., 1997). Thus, reliable analytical methods are essential to detect and quantify protein modifications. Based on the mechanisms of separation, these methods can be divided into two groups: size-based and chemistry of amino acid side chains. Size-based separation methods include size-exclusion chromatography (SEC), sodium dodecyl sulfate-polyacrylamide gel electrophoresis (SDS-PAGE) and capillary electrophoresis with SDS (CE-SDS) (Dada, Rao, Jones, Jaya, \& Salas-Solano, 2017; Davagnino, Wong, Shelton, \& Mankarious, 1995; H. Liu, Gaza-Bulseco, \& Chumsae, 2009; Rao \& Kroon). Other separation methods typically include various types of chromatography based on the charge and hydrophobicity differences of these species. In addition to the above methods for monitoring and quantitation of protein fragmentation during process development and quality release testing, the identification of the exact cleavage site and further characterization of these fragments are accomplished using mass spectrometry (MS) (H. Liu, Gaza-Bulseco, \& Lundell, 2008).

Size-based separation methods are often straightforward due to the physical size differences, while other chemical degradations of amino acid side chains are not easily detected. Peptide bond cleavage becomes detectable only after two fragments are separated. In addition, non-covalent interactions such as hydrophobic interactions between these disulfide-reduced species may prevent separation of the two fragments under native conditions. Thus, denaturation may be required to detect the cleavages in a folded immunoglobulin domain. In contrast, the cleavage in the hinge region is readily detectable by SEC under a native condition. SEC and non-reduced CE-SDS results of a partially reduced sample showed that its native structure was intact although the majority of inter chain disulfide bonds were broken (Figure S3).

In recent years, CE-SDS method has emerged as a valuable alternative to conventional SDS-PAGE method for the characterization and automatic quantitation of antibodies (Krylov \& Dovichi, 2000). By providing an excellent resolution of fragments, CE-SDS methods have been widely used in biotech industry to monitor overall fragmentation during process development and is now commonly used for final drug substance and drug product GMP release and in-process testing due to the straightforward quantification and improved sensitivity with fluorescence detection (Cherkaoui et al., 2010). Additionally, in recent years chip-based protein characterization system has been utilized to offer an automated alternative to traditional methods 
by streamlining slab gel electrophoresis, while also providing high throughput and data quality required by bio-therapeutics and genomics workflows (Wagner et al., 2020).

SEC is usually considered as the gold standard method for quantitation of aggregates, but it is rarely used to quantify fragmentation since fragments may co-elute with the monomer peak and lead to poor resolution (Ricker \& Sandoval, 1996). For this reason, SEC can be run under denaturing conditions (dSEC), such as in the presence of guanidine hydrochloride, SDS, or an organic solvent in mobile phases or during sample preparation (H. Liu et al., 2009). Denaturing SEC is an alternative separation method to quantitatively determine protein fragments. Similar to SDS-based methods, the protein is denatured using denaturing reagent such as $6 \mathrm{M}$ guanidine at $50{ }^{\circ} \mathrm{C}$ for 60 minutes and injected onto a SEC column with mobile phase containing guanidine. The denaturing reagent will detach fragments from association before separation on SEC column. The separation resolution of denature SEC may not be as good as SDS-based methods. However, due to its relative high loading amount, the denaturing SEC can be a useful tool to separate and isolate fragment species for further characterization. Denaturing SEC coupled with MS is a very powerful tool to characterize protein fragments (García, 2005; H. Xie et al., 2010). The denaturing SEC-MS can be operated as an in-line method that uses organic solvent in the SEC mobile phase followed by MS detection. The organic solvent serves as a denaturing reagent to detach IgG light chains from heavy chains before SEC separation, allowing the mass spectrometer to measure the dissociated IgG heavy and light chains. For example, the improved SE-UPLC coupled with MS employing mobile phases containing acetonitrile (ACN), trifluoroacetic acid (TFA), and formic acid allowed the separation of antibody light chain and heavy chain, and to obtain a direct molecular weight measurement (H. Liu et al., 2009; R. Yang et al., 2015).

In recent years, significant progress has been made in process analytical technology (PAT), which enables realtime monitoring and control, to maintain consistent product quality through better process understanding (Jenzsch et al., 2018; Read, Park, et al., 2010; Read, Shah, et al., 2010). Real time monitoring of bioprocess with the integration of analytics at critical unit operations of processes is one of the paramount necessities for implementing real time release of biopharmaceuticals (Chemmalil et al., 2020; Wasalathanthri et al., 2020). For example, protein purity, a critical quality attribute (CQA), can be monitored using a variety of PAT tools during downstream operations (Großhans et al., 2018; Patel et al., 2018). Another example, a PAT application using the denaturing SEC, can be integrated with the Protein A chromatography to provide real-time data of product purity and to enforce necessary process control strategies to ensure product quality (Chemmalil et al., 2020).

\section{APPROACHES TO MINIMIZE DISULFIDE BOND REDUCTION AND RECOVER of REDUCED-MAB}

\subsection{Overview}

As discussed above, disulfide bond reduction exists during mAb manufacturing process and impacts $\mathrm{mAb}$ stability, thus minimizing the disulfide bond reduction is critical to ensure high process yield and purity of the final drug substance. Since enzyme catalyzed redox reaction is primarily the root cause of disulfide bond reduction, different approaches that inhibit or slow down the redox reaction, directly or indirectly, have been applied in the manufacturing process to eliminate the disulfide bond reduction. Generally, these prevention approaches are applied at relatively upstream manufacture steps, such as cell culture, cell culture fluid harvest and storage (Figure 5, Table 1). However, the disulfide bond reduction prevention approaches do have some limitations such as prolonging operation time, increasing equipment cost and decreasing operational flexibility. To keep the flexibility and efficiency of the manufacturing process, approaches to rescue the reduced mAbs and to savage "waste" batches should also be considered to address the disulfide bond reduction challenges. Redox systems can be introduced to chromatography steps during the manufacturing process to rescue previously reduced mAbs (Figure 5, Table 1), and the rescued mAbs showed comparable properties as intact $\mathrm{mAb}$ with no negative impact on final drug product quality (Tan et al., 2020).

\subsection{Development of scale-down models for disulfide bond reduction study}

It was reported that the disulfide bond reduction was mostly observed during the manufacturing-scale pro- 
cess, but not very often observed during the lab-scale process (Du et al., 2018; Kao et al., 2010). Also the disulfide bond reduction level could vary significantly during the manufacturing process (Du et al., 2018; Kao et al., 2010; O'Mara et al., 2019; Trexler-Schmidt et al., 2010). Thus, it is critical to develop a reliable scale-down model to demonstrate disulfide bond reduction for lab-scale studies. A general approach is to create a worst-case disulfide bond reduction sample, where HCCF is completely homogenized to release intracellular enzymes that cause disulfide bond reduction. Then the lysed HCCF can mix with non-lysed HCCF at different ratios to create samples with different levels of disulfide bond reduction (Du et al., 2018; Trexler-Schmidt et al., 2010). Furthermore, to prevent free thiol re-oxidization, clarified bulks (CB) were purged with $\mathrm{N}_{2}$ gas and stored at room temperature under anaerobic environment (Du et al., 2018).

\subsection{Disulfide bond reduction prevention methods}

As shown in Figure 5, multiple approaches can be applied to prevent (or eliminate) the disulfide bond reduction at different manufacturing steps. Based on their impact on the enzyme catalyzed redox reaction, we categorized these approaches into four types:

\subsubsection{Inhibit enzyme over expression in the cells.}

Trx is the terminal enzyme that is responsible for disulfide bond reduction. If the cells cannot overexpress Trx, the enzyme system activity is significantly inhibited. Koterba et al. demonstrated the reduced disulfide reduction by using Trx knock out CHO cells. Their research showed that inhibiting Trx overexpression did not affect the overall cell growth (Koterba et al., 2012). By incubating cell lysate with intact IgG for 24 hours, there is still higher than $50 \%$ intact IgG remaining in engineered cell lysate (without Trx overexpression) pool, while in the control cell lysate (with Trx overexpressed) the intact IgG is close to $0 \%$. This result showed that it is possible to inhibit the Trx overexpression in cells and minimize disulfide bond reduction caused by cell lysis. However, this way of controlling disulfide reduction depends on concentrations of other enzymes: if concentrations of other enzymes are high, the redox reaction still can be catalyzed efficiently and result in high level of disulfide bond reduction.

\subsubsection{Inhibit enzyme activity}

Metal ions and chelation can inhibit different steps of enzyme catalyzed redox reaction. For instance, Ethylenediaminetetraacetic acid (EDTA) can inhibit hexokinase activity and reduce the formation of glucose-6-P. $\mathrm{Cu}^{2+}, \mathrm{Zn}^{2+}, \mathrm{Hg}^{2+}$ and $\mathrm{Co}^{2+}$ can inhibit Trx activity. Aurothioglucose (ATG) and aurothiomalate (ATM) can inhibit TrxR activity (Kao et al., 2010). Inhibitors can be introduced at earlier manufacture steps, such as cell culture media or HCCF (before and after filtration) with the final concentration of inhibitors are at micro-molar to milli-molar levels. Previous research showed that if the inhibitor efficiency is high, it can completely inhibit disulfide bond reduction during 2-3 days HCCF storage time (Trexler-Schmidt et al., 2010). However, studies on the inhibitor performances when HCCF storage time is longer were limited and may need further investigation.

\subsubsection{Reduce the amount of enzyme present}

Disulfide bond reduction can also be minimized if there is less enzyme available to catalyze the disulfide bond redox reaction. One approach is to introduce components that can react with the enzyme as competing reaction pathways to consume the enzyme so it becomes unavailable for disulfide bond reduction. As discussed in root-cause analysis section, $\mathrm{O} 2$ can react with NADPH; thus improving DO levels in HCCF can minimize disulfide bond reduction (Handlogten, Wang, \& Ahuja, 2020; Mun et al., 2015). For instance, researchers found that keeping a minimum $30 \%$ DO level by air sparging can prevent disulfide bond reduction and maintain higher than $90 \%$ intact $\mathrm{mAb}$. Besides $\mathrm{O}_{2}, \mathrm{H}_{2} \mathrm{O}_{2}$ and L-cystine with optimal concentration can also react with enzyme and reduce the available enzyme for disulfide bond reduction. Consequently, researchers induced micro-molar level $\mathrm{H}_{2} \mathrm{O}_{2}$ and L-cystine to the $\mathrm{HCCF}$ to eliminate disulfide bond reduction (Chung et al., 2017; Du et al., 2018). Another approach is to minimize cell lysis during CCF harvest step, consequently there will be less enzyme secreted into CCF. This can be achieved by minimizing cell shear force in harvest step, such as using a hermetic style centrifuge (Trexler-Schmidt et al., 2010), or controlling the depth filtration 
differential pressure lower than certain values (O'Mara et al., 2019).

\subsubsection{Decrease enzymatic reaction rate and reduce reaction time}

Lowering $\mathrm{pH}$ and temperature of HCCF or reducing HCCF storage time can slow down the enzymatic reaction. These approaches can be coupled with other methods to further eliminate disulfide bond reduction. It should be noted that lowing $\mathrm{pH}$ is less frequently used since it changes microenvironment around $\mathrm{mAb}$ and may cause mAb aggregation (Trexler-Schmidt et al., 2010).

While there are different approaches to minimize disulfide bond reduction in manufacturing process, these approaches have some limitations: (1) inhibition of enzyme overexpression genetically in cells may increase the $\mathrm{mAb}$ development time, also this may increase the risk of not overexpressing the mAb correctly since the genetically modified mutant clone may not survive in antibody selection process at the first stage; (2) the type and the concentration of the inhibitors that eliminate disulfide bond reduction may vary with each mAbs, thus optimizing the inhibitor selection could be time-consuming; (3) the final inhibitor concentration present in drug substance needs be monitored and controlled, and it may require extra manufacturing steps to remove the inhibitors to meet the drug substance GMP release specifications for clearances; (4) air sparging, lowering the storage temperature and reducing the storage time may require extra financial investment for equipment thus increase the cost of the manufacturing process and reduce the flexibility of manufacturing process. Consequently, developing approaches to recover (or "savage") the reduced disulfide bond should be considered in the manufacturing development process.

\subsection{Rescue reduced mAb during downstream processing}

Due to the limitations of operation flexibility and efficiency of controlling disulfide bond reduction, saving and recovering the already reduced mAb becomes a compelling alternative approach. Compared to the elimination approach, the recovery approach has advantages including: (1) saving the "waste" reduced mAbs, (2) further lowing the risks of mAb disulfide bond reduction in downstream process steps, (3) more flexible and economically favorable since this approach requires neither extra equipment nor extra operation steps.

Reduced $\mathrm{mAb}$ recovery involves the thiol-disulfide exchange reaction between the reduced mAb and a redox reagent (Bulleid \& Ellgaard, 2011; Mamathambika \& Bardwell, 2008). The thiol-disulfide exchange reaction includes two steps (Figure S4). In the first step, the nucleophilic thiolate group (S-) formed by free thiol deprotonation attacks one of the sulfur atoms of the redox reagent, and a disulfide bond forms between the redox reagent and the $\mathrm{mAb}$ (Figure $\mathrm{S} 4 \mathrm{~A}$ ); in the second step, the remaining thiol group in $\mathrm{mAb}$ attacks the newly formed disulfide bond, releases the redox reagent and forms disulfide bond in mAb (Figure S4B). While the thiol-disulfide exchange reaction has been widely studied to provide deeper understanding of disulfide bond formation relations in cells (Cappel \& Gilbert, 1988; Østergaard, Tachibana, \& Winther, 2004; Tu, HoSchleyer, Travers, \& Weissman, 2000), there are very few research in literature that applied this reaction to recover reduced $\mathrm{mAb}$ in the manufacturing process. In our recent in-house studies, we successfully recovered the reduced $\mathrm{mAb}$ by using redox reagent buffer cysteine/cystine as wash buffer in Protein A chromatography step (Figure S5, data not shown) (Tan et al., 2020; Tang et al., 2020). Based on the kinetic model developed in this study, the cysteine/cystine concentration, $\mathrm{pH}$ and $\mathrm{mAb} /$ redox buffer contact time were optimized to recover the disulfide reduced $\mathrm{mAb}$. The results showed that mAb purity was improved from $<5 \%$ in the load to $>90 \%$ in the elution. Cystine concentration and $\mathrm{pH}$ were found to be the most critical factors that affected reduced mAb recovery. To achieve a high mAb recovery ratio, buffer $\mathrm{pH} 8$ to 10 and a minimum of 60 minutes mAb/redox buffer contact time was recommended from this study. The recovered mAb showed comparable properties to original intact mAb based on a variety of biochemical and biophysical analytical characterization. The studies demonstrated the feasibilities of applying recovery methods in downstream process to produce acceptable quality mAb product for potential clinical uses.

\subsection{Disulfide bond reduction prediction and monitoring during manufacturing process}

Besides disulfide bond reduction elimination approaches and recovering already reduced mAb approaches summarized above, proactively applying the process analytical technology (PAT) for disulfide bond reduction 
prediction and on-line/at-line monitoring during the manufacturing development process is also important (Chemmalil et al., 2020). PAT enables the detection of the disulfide bond reduction in early process steps thus allows the proper monitoring, and the prevention methods or rescue methods to be applied in time to ensure final product quality. In addition, the real-time analytical results of disulfide bond reduction can provide a quantitative understanding of the root cause of the disulfide bond reduction in manufacturing process and allow more efficient control to improve process design (Read, Park, et al., 2010; Read, Shah, et al., 2010; Simon et al., 2015).

It was also reported that, the correlation between cell culture redox potential and antibody reduction can be applied to predict sulfide bond reduction levels in early manufacturing process steps (Handlogten et al., 2020). Through online cell culture redox potential measurements and analyzing the amount of intact $\mathrm{mAb}$ at late stage of cell culture such as on Day 12 and Day 14, a redox potential of $-70 \mathrm{mV}$ was found to be used as a cell culture redox potential threshold for an IgG2. Above this redox potential, there was minimal level of disulfide bond reduction while below this redox potential, the disulfide bond reduction level could vary significantly. These researchers further designed a redox reduction control system to maintain the cell culture redox potential higher than the threshold by adding CuSO4 and /or improving DO level, and demonstrated the success in keeping the disulfide bond reduction level of cell culture at a minimal level.

In addition to using redox potential as a predictive tool during cell culture step, free thiol levels in HCCF can also be controlled to predict disulfide bond reduction level and appropriate measures may be taken to mitigate the risk. In a typical monoclonal antibody manufacturing process with the Chinese Hamster Ovary (CHO) cell line, we have established three critical thresholds of free thiols in HCCF based on the disulfide reduction risk: $<100 \mu \mathrm{M}$ (low risk); $100-200 \mu \mathrm{M}$ (medium risk) and $>200 \mu \mathrm{M}$ (high risk) (Du et al., 2018). For the high risk $\mathrm{HCCF}$, in addition to low temperature storage and maintaining aeration, the harvested material is processed through Protein A chromatography as early as possible. To further de-risk the possible disulfide reduction, each elution pools are kept separately if multiple Protein A run cycles are performed.

For the downstream process steps such as Protein A chromatography and ion exchange chromatography, currently there are no reported research on applying on-line analysis methods for disulfide bond reduction. However, the success of incorporating on-line liquid chromatography (LC) for charge variant (Alvarez et al., 2011) and size variant analysis (Chemmalil et al., 2020) showed the potential of on-line disulfide bond reduction monitoring and analysis. Alvarez et al designed an in-house on-line liquid chromatography (LC)-mass spectrometry (MS) system that can directly trap fractions of interests from ion exchange chromatography (IEC) and size exclusion chromatography (SEC) to the reversed phase (RP) trap cartridges for desalting then subsequently analyze the fraction sample in MS (Alvarez et al., 2011). They successfully identified mAb charge variants due to different levels of glycosylation with this system. In recent years, commercial on-line process analysis systems have been developed. Patel and coworkers developed an on-line ion exchange LC using commercial PATROL@ UPLC Process Analysis System (Patel et al., 2017), where sample pooling during downstream operations were guided based on near real time charge variant analysis. The commercial PATROL UPLC Process Analysis System used in Patel's study can also be applied to develop the on-line SEC detection. In our recent in-house study an on-line SEC setup showed the capability of investigating IEC fraction size variant compositions (LMW, monomer, and HMW) under both native condition and denaturing condition (Chemmalil et al., 2020), and may be developed for disulfide reduced mAb identification in the future.

\section{CASE STUDY ON DISULFIDE BOND REDUCTION ELIMINATION AND DISULFIDE REDUCED MAB RECOVERY}

This case study illustrates an example of controlling disulfide bond reduction by using both a preventive strategy and a rescue strategy in manufacturing process, as detailed in Section 6 and illustrated in Figure 5. In brief, the preventive strategy essentially applied the temperature control as well as oxygen control to prevent disulfide reduction, and the rescue strategy demonstrated that the "waste" disulfide reduced antibody could still be rescued and recovered by re-oxidizing the reduced disulfide bonds during Protein A chromatography. 
Figure $6 \mathrm{~A}$ illustrates a comprehensive study plan, in which HCCFs of three mAbs (mAb-1, mAb-2, and mAb3) were used for the study (Tan et al., 2020). Each HCCF was divided into two pools, which underwent two treatments and storage conditions: "good HCCF" (air sparging $+4{ }^{\circ} \mathrm{C}$ ) and "bad HCCF" (nitrogen sparging + room temperature $\left(19^{\sim} 25{ }^{\circ} \mathrm{C}\right)$ ). Both HCCFs were processed through Protein A purification using two Wash 2 buffers (Control buffer and Redox buffer), respectively. Figures $6 \mathrm{~B}$ and 6C compare product purity and aggregation using two Protein A wash arms for the three mAbs in both intact and reduced forms. It was observed that "good HCCFs" for all three mAbs maintained high product purity using both wash arms, suggesting that the preventive strategy (chilled storage temperature of harvested bulk with dissolved oxygen) was able to prevent the disulfide bond reduction prior to Protein A step. In contrast, "bad HCCFs" using the control wash condition (arm 1: high pH without redox wash) showed low purity $(<50 \%)$ for all three mAbs. However, high product purity was obtained by using the redox wash (arm 2), which demonstrated the effectiveness of redox wash to enhance the disulfide bond reformation on the Protein A column.

Implementation of either preventive strategy or rescue strategy or both clearly demonstrated that disulfide reduction issue could be resolved to achieve high-purity antibody product. Furthermore, this case study demonstrated that the redox wash has no negative impact on process yield or product quality. Extensive characterization of the recused antibody confirmed a complete formation of interchain disulfide bonds and comparable biophysical properties to the reference material. The detailed study was published in a separate paper (Tan et al., 2020).

\section{CONCLUSIONS AND FUTURE PERSPECTIVES}

The disulfide bond reduction during the biologics manufacturing process are getting more and more attention currently in the biotech industry as it is a frequently encountered technical challenge and its effective management will help meet critical requirement for protein quality specifications and therapy efficiency. In this paper, we reviewed the root cause of disulfide bond reduction, analytical methods for disulfide bond reduction analysis, as well as disulfide bond reduction elimination and recovery approaches. Furthermore, we suggest additional aspects of disulfide bond reduction issue worth being addressed in future antibody manufacturing development:

\subsection{Minimizing disulfide bond reduction and rescue disulfide bond in purification platform}

While it is difficult to adapt a truly pre-defined process for different individual mAb purification, the platform development approaches based on common unit operations have been proposed by many biopharmaceutical companies (Kelley, Blank, \& Lee, 2009; Shukla, Hubbard, Tressel, Guhan, \& Low, 2007). Since disulfide bond reduction mainly happens at the beginning of the purification process, the cell culture harvest and Protein A chromatography could be the main unit operations to align the strategy for disulfide bond reduction elimination and recovery approaches. For the harvest step, disk-stack continuous centrifuge is applied as a standard operation for large scale cell culture harvest and clearance. However, as discussed in previous sections, the cell lysis during the cell culture harvest may release intracellular enzymes, and lead to disulfide bond reduction. To address this issue, fully hermetic centrifuge may be used as platform harvest equipment. Compared with the disk-stack continuous centrifuge, the hermetic centrifuge machine can be fully filled with liquid to eliminate the air-liquid surface, which is known to be one of the root causes for cell lysis $(\mathrm{H}$. F. Liu, Ma, Winter, \& Bayer, 2010). Hermetic centrifuge machine is commercially available (Rose, 2008), however, operation parameters such as throughput, process speed and time need to be further optimized from facility fit perspective. Another direction to align the strategy of the disulfide bond reduction elimination approaches during cell culture harvest is using computational fluid dynamic simulation (CFD) to optimize centrifuge parameters. CFD can simulate the shear stress and support the estimation of cell lysis level under certain centrifuge operation conditions (Boychyn et al., 2004; Megson, Wilson, \& MacGregor, 2002; MolinaMiras, Sánchez-Mirón, García-Camacho, \& Molina-Grima, 2018). For Protein A chromatography step, using redox reagent buffer during wash step can successfully recover the reduced $\mathrm{mAb}$. This could be aligned with platform wash buffer to recover the disulfide-reduced $\mathrm{mAb}$ or further reduce risk of the disulfide bond reduction for the intact mAb (Tan et al., 2020; Tang et al., 2020). 


\subsection{Identifying disulfide bond reduction risks using machine learning algorithms}

In recent years, machine learning algorithms have been developed rapidly and started to gain more and more attention in the pharmaceutical industry. Several machine learning algorithms have been applied to predict $\mathrm{mAb} \mathrm{pH}$ stability, thermal stability and chemical stability (Jia \& Sun, 2017; King et al., 2011; Sankar et al., 2018). For instance, Sankar et al predicted mAb methionine oxidation risk based on a random forest prediction model (Sankar et al., 2018). In their studies, mAb structure-based features, sequence-based features and dynamic-based features were extracted as input data, and mAb peptide mapping results on oxidation were extracted as output data for model training. Similar machine learning algorithms were also developed recently for mAb deamidation risks prediction (Delmar, Wang, Choi, Martins, \& Mikhail, 2019; Jia \& Sun, 2017). The success of machine learning in predicting the mAb biophysical and biochemical stabilities provides the possibilities of applying machine learning algorithm to predict $\mathrm{mAb}$ disulfide bond reduction risks. One proposed approach is to use different $\mathrm{mAb}$ sequence-based features, 3 -D structure-based features as data input, and CE NR-SDS analytical results as output features for model training. One of advantages of the machine learning prediction is to identify, in very early development stage, the mAbs that show high disulfide bond reduction risks. If the "easily reduced" mAb can be recognized early, an alternative mAb candidate can be selected to avoid the disulfide bond reduction, or the downstream development researchers can start to optimize the manufacturing process early enough to address the challenge. Another advantage of the machine learning approach is that it could identify the features such as structure-based features, sequencebased features and dynamic-based features that have higher impacts on mAbs disulfide bond reduction, and provide insights on the disulfide bond reduction level differences observed in different molecules. However, machine learning algorithm has its own challenges at this early stage of its development, and people should be aware of: (1) the data could be unbalanced, for instance, if there are more mAbs that show low disulfide bond reduction risk than $\mathrm{mAbs}$ that show high risks. This could increase the false positive and false negative prediction rate; (2) the data sets may be not large enough. The number of data sets are around 100 200 in existing research mentioned earlier. Thus, some advanced machine learning algorithms such as neural network or gradient boosting may not be able to be applied, otherwise it may lead to overfitting issues.

\subsection{Disulfide bond reduction during multi-specific antibody purification}

Though multi-specific antibodies (BsAbs and TsAbs) have not been as widely manufactured as monoclonal antibodies, there is a growing interest in multi-specific antibody purification in the biopharmaceutical industry in recent years (Brinkmann \& Kontermann, 2017; Y. Li, 2019; Swope et al., 2020; Tustian et al., 2016; X. Yang et al., 2015). Taking BsAb as examples, during bispecific antibody purification process, the inter-chain disulfide bond between the heavy chains in two parental mAbs need to be reduced first to generate half-mers and followed by free thiol oxidization to form bispecific antibodies. For instance, one method for bispecific antibody purification is to capture parental mAb using Protein A chromatography separately followed by incubating mixed parental mAbs in phosphate-buffered saline (PBS) buffer that contains 2-MEA (reducing agent) for disulfide bond reduction. Then the mixture is re-oxidized by dialysis against PBS buffer without 2-MEA (Paul et al., 2016). In addition to purification process, disulfide bond reduction and re-oxidization also influence bispecific antibody stabilities and impurities level. Researchers found that intact bispecific antibody are susceptible to the reduction condition. Compared with $\mathrm{mAbs}$, disulfide bond reduction for BsAbs is much more severe, since it could lead to both aggregation and mispairing. Higher HMW levels have also been observed for the bispecific antibody when the bispecific antibody and the parental mAb were reduced and re-oxidized under similar conditions. In addition, disulfide bond mispairing may lead to homodimer formation(Kuglstatter et al., 2017). Thus, both disulfide bond reduction elimination and its recovery are critical for bispecific antibody processing, and the learnings on mAb disulfide bond reduction could also benefit bispecific antibody development.

\section{Acknowledgements}

The authors would like to acknowledge Process Development Analytics for their contributions to this work. The authors also thank Dr. Magfur Alam, Dr. Dhanuka Wasalathanthri and Dana Brandariz for providing thorough review and invaluable comments. All financial support was provided by BMS: T.R., Z.T., V.E., 
A.L., S.G., and Z.L. are employees of BMS. The authors have no conflicts of interest to declare.

\section{Disclosure of potential conflicts of interest}

No potential conflicts of interest were disclosed.

\section{REFERENCES}

Alvarez, M., Tremintin, G., Wang, J., Eng, M., Kao, Y.-H., Jeong, J., . . . Borisov, O. V. (2011). On-line characterization of monoclonal antibody variants by liquid chromatographymass spectrometry operating in a two-dimensional format. Analytical Biochemistry, 419 (1), 17-25. doi:https://doi.org/10.1016/j.ab.2011.07.033

Amzel, L. M., \& Poljak, R. J. (1979). Three-Dimensional Structure of Immunoglobulins. Annual Review of Biochemistry, 48 (1), 961-997. doi:10.1146/annurev.bi.48.070179.004525

Andya, J. D., Hsu, C. C., \& Shire, S. J. (2015). Mechanisms of aggregate formation and carbohydrate excipient stabilization of lyophilized humanized monoclonal antibody formulations. AAPS PharmSci, 5 (2), 21. doi:10.1208/ps050210

Bessa, J., Boeckle, S., Beck, H., Buckel, T., Schlicht, S., Ebeling, M., . . . Iglesias, A. (2015). The Immunogenicity of Antibody Aggregates in a Novel Transgenic Mouse Model. Pharmaceutical Research, 32 (7), 2344-2359. doi:10.1007/s11095-015-1627-0

Boychyn, M., Yim, S. S. S., Bulmer, M., More, J., Bracewell, D. G., \& Hoare, M. (2004). Performance prediction of industrial centrifuges using scale-down models. Bioprocess and Biosystems Engineering, 26 (6), 385-391. doi:10.1007/s00449-003-0328-y

Brinkmann, U., \& Kontermann, R. E. (2017). The making of bispecific antibodies. mAbs, 9 (2), 182-212. doi:10.1080/19420862.2016.1268307

Bulleid, N. J., \& Ellgaard, L. (2011). Multiple ways to make disulfides. Trends in Biochemical Sciences, 36 (9), 485-492. doi:https://doi.org/10.1016/j.tibs.2011.05.004

Cappel, R. E., \& Gilbert, H. F. (1988). Thiol/disulfide exchange between 3-hydroxy-3-methylglutaryl-CoA reductase and glutathione. A thermodynamically facile dithiol oxidation. Journal of Biological Chemistry, 263 (25), 12204-12212.

Caravella, J., \& Lugovskoy, A. (2010). Design of next-generation protein therapeutics. Current Opinion in Chemical Biology, 14 (4), 520-528. doi:https://doi.org/10.1016/j.cbpa.2010.06.175

Carter, P. (2001). Bispecific human IgG by design. Journal of Immunological Methods, 248 (1), 7-15. doi:https://doi.org/10.1016/S0022-1759(00)00339-2

Chakravarthi, S., \& Bulleid, N. J. (2004). Glutathione Is Required to Regulate the Formation of Native Disulfide Bonds within Proteins Entering the Secretory Pathway. Journal of Biological Chemistry, 279 (38), 39872-39879.

Chemmalil, L., Prabhakar, T., Kuang, J., West, J., Tan, Z., Ehamparanathan, V., . . Li, Z. (2020). Online/atline measurement, analysis and control of product titer and critical product quality attributes (CQAs) during process development. Biotechnol Bioeng . doi:10.1002/bit.27531

Chen, X., Nguyen, M., Jacobson, F., \& Ouyang, J. (2009). Charge-based analysis of antibodies with engineered cysteines. $m A b s, 1$ (6), 563-571. doi:10.4161/mabs.1.6.10058

Cheng, Y., Chen, M. T., Patterson, L. C., Yu, X. C., Zhang, Y. T., Burgess, B. L., \& Chen, Y. (2017). Domainspecific free thiol variant characterization of an IgG1 by reversed-phase high-performance liquid chromatography mass spectrometry. Analytical Biochemistry, 519 , 8-14. doi:https://doi.org/10.1016/j.ab.2016.12.003 
Cherkaoui, S., Bettinger, T., Hauwel, M., Navetat, S., Allémann, E., \& Schneider, M. (2010). Tracking of antibody reduction fragments by capillary gel electrophoresis during the coupling to microparticles surface. Journal of Pharmaceutical and Biomedical Analysis, 53 (2), 172-178. doi:https://doi.org/10.1016/j.jpba.2010.01.039

Chung, W. K., Russell, B., Yang, Y., Handlogten, M., Hudak, S., Cao, M., . . . Zhu, M. (2017). Effects of antibody disulfide bond reduction on purification process performance and final drug substance stability.Biotechnology and Bioengineering, 114 (6), 1264-1274. doi:10.1002/bit.26265

Correia, I. (2010). Stability of IgG isotypes in serum. mAbs, 2 (3), 221-232. doi:10.4161/mabs.2.3.11788

Cromwell, M. E. M., Hilario, E., \& Jacobson, F. (2006). Protein aggregation and bioprocessing. The AAPS Journal, 8 (3), E572-E579. doi:10.1208/aapsj080366

Cui, Y., Cui, P., Chen, B., Li, S., \& Guan, H. (2017). Monoclonal antibodies: formulations of marketed products and recent advances in novel delivery system. Drug Development and Industrial Pharmacy, 43 (4), 519-530. doi:10.1080/03639045.2017.1278768

Dada, O. O., Rao, R., Jones, N., Jaya, N., \& Salas-Solano, O. (2017). Comparison of SEC and CE-SDS methods for monitoring hinge fragmentation in IgG1 monoclonal antibodies. Journal of Pharmaceutical and Biomedical Analysis, 145 , 91-97. doi:https://doi.org/10.1016/j.jpba.2017.06.006

Davagnino, J., Wong, C., Shelton, L., \& Mankarious, S. (1995). Acid hydrolysis of monoclonal antibodies. Journal of Immunological Methods, 185 (2), 177-180. doi:https://doi.org/10.1016/0022-1759(95)00110-V

Delmar, J. A., Wang, J., Choi, S. W., Martins, J. A., \& Mikhail, J. P. (2019). Machine Learning Enables Accurate Prediction of Asparagine Deamidation Probability and Rate. Molecular Therapy - Methods 86 Clinical Development, 15 , 264-274. doi:https://doi.org/10.1016/j.omtm.2019.09.008

Dowd, S. E., Halonen, M. J., \& Maier, R. M. (2009). Chapter 12 - Immunological Methods. In R. M. Maier, I. L. Pepper, \& C. P. Gerba (Eds.), Environmental Microbiology (Second Edition) (pp. 225-241). San Diego: Academic Press.

Du, C., Huang, Y., Borwankar, A., Tan, Z., Cura, A., Yee, J. C., . . . Li, Z. J. (2018). Using hydrogen peroxide to prevent antibody disulfide bond reduction during manufacturing process. mAbs, 10 (3), 500-510. doi:10.1080/19420862.2018.1424609

Ecker, D. M., Jones, S. D., \& Levine, H. L. (2015). The therapeutic monoclonal antibody market. $m A b s, 7$ (1), 9-14. doi:10.4161/19420862.2015.989042

Edelman, G. M., \& Gall, W. E. (1969). The Antibody Problem.Annual Review of Biochemistry, 38 (1), 415-466. doi:10.1146/annurev.bi.38.070169.002215

Edelman, G. M., \& Gally, J. A. (1962). The nature of Bence-Jones proteins. Chemical similarities to polypetide chains of myeloma globulins and normal gamma-globulins. The Journal of experimental medicine, 116 (2), 207-227. doi:10.1084/jem.116.2.207

Elgundi, Z., Reslan, M., Cruz, E., Sifniotis, V., \& Kayser, V. (2017). The state-of-play and future of antibody therapeutics. Advanced Drug Delivery Reviews, 122 , 2-19. doi:https://doi.org/10.1016/j.addr.2016.11.004

Fass, D. (2012). Disulfide Bonding in Protein Biophysics. Annual Review of Biophysics, 41 (1), 63-79. doi:10.1146/annurev-biophys-050511-102321

García, M. C. (2005). The effect of the mobile phase additives on sensitivity in the analysis of peptides and proteins by high-performance liquid chromatography-electrospray mass spectrometry. Journal of Chromatography B, 825 (2), 111-123. doi:https://doi.org/10.1016/j.jchromb.2005.03.041

Gilbert, H. F. (1995). [2] Thiol/disulfide exchange equilibria and disulfidebond stability. In Methods in Enzymology (Vol. 251, pp. 8-28): Academic Press. 
Großhans, S., Rüdt, M., Sanden, A., Brestrich, N., Morgenstern, J., Heissler, S., \& Hubbuch, J. (2018). In-line Fourier-transform infrared spectroscopy as a versatile process analytical technology for preparative protein chromatography. Journal of Chromatography A, 1547 , 37-44. doi:https://doi.org/10.1016/j.chroma.2018.03.005

Handlogten, M. W., Wang, J., \& Ahuja, S. (2020). Online control of cell culture redox potential prevents antibody interchain disulfide bond reduction. Biotechnology and Bioengineering, 117 (5), 1329-1336. doi:10.1002/bit.27281

Handlogten, M. W., Zhu, M., \& Ahuja, S. (2017). Glutathione and thioredoxin systems contribute to recombinant monoclonal antibody interchain disulfide bond reduction during bioprocessing. Biotechnology and Bioengineering, 114 (7), 1469-1477. doi:10.1002/bit.26278

Harris, R. J. (2005). Heterogeneity of recombinant antibodies: linking structure to function. Dev Biol (Basel), 122 , 117-127. Retrieved from https://www.ncbi.nlm.nih.gov/pubmed/16375256

Holmgren, A. (1979). Thioredoxin catalyzes the reduction of insulin disulfides by dithiothreitol and dihydrolipoamide. Journal of Biological Chemistry, 254 (19), 9627-9632.

Holmgren, A., \& Lu, J. (2010). Thioredoxin and thioredoxin reductase: Current research with special reference to human disease.Biochemical and Biophysical Research Communications, 396 (1), 120-124. doi:https://doi.org/10.1016/j.bbrc.2010.03.083

Hughes, B. (2010). 2009 FDA drug approvals. Nature Reviews Drug Discovery, 9 (2), 89-92. doi:10.1038/nrd3101

Huh, J. H., White, A. J., Brych, S. R., Franey, H., \& Matsumura, M. (2013). The identification of free cysteine residues within antibodies and a potential role for free cysteine residues in covalent aggregation because of agitation stress. J Pharm Sci, 102 (6), 1701-1711. doi:10.1002/jps.23505

Hutterer, K. M., Hong, R. W., Lull, J., Zhao, X., Wang, T., Pei, R., . . Flynn, G. C. (2013). Monoclonal antibody disulfide reduction during manufacturing. $m A b s, 5$ (4), 608-613. doi:10.4161/mabs.24725

Imai, K., \& Takaoka, A. (2006). Comparing antibody and small-molecule therapies for cancer. Nature Reviews Cancer, 6 (9), 714-727. doi:10.1038/nrc1913

Jenzsch, M., Bell, C., Buziol, S., Kepert, F., Wegele, H., \& Hakemeyer, C. (2018). Trends in Process Analytical Technology: Present State in Bioprocessing. In B. Kiss, U. Gottschalk, \& M. Pohlscheidt (Eds.),New Bioprocessing Strategies: Development and Manufacturing of Recombinant Antibodies and Proteins (pp. 211252). Cham: Springer International Publishing.

Jia, L., \& Sun, Y. (2017). Protein asparagine deamidation prediction based on structures with machine learning methods. PLOS ONE, 12 (7), e0181347. doi:10.1371/journal.pone.0181347

Johnson, S., Burke, S., Huang, L., Gorlatov, S., Li, H., Wang, W., . . . Bonvini, E. (2010). Effector Cell Recruitment with Novel Fv-based Dual-affinity Re-targeting Protein Leads to Potent Tumor Cytolysis and in Vivo B-cell Depletion. Journal of Molecular Biology, 399 (3), 436-449. doi:https://doi.org/10.1016/j.jmb.2010.04.001

Kao, Y.-H., Hewitt, D. P., Trexler-Schmidt, M., \& Laird, M. W. (2010). Mechanism of antibody reduction in cell culture production processes.Biotechnology and Bioengineering, 107 (4), 622-632. doi:10.1002/bit.22848

Kelley, B., Blank, G., \& Lee, A. (2009). Downstream Processing of Monoclonal Antibodies: Current Practices and Future Opportunities. 1-23. doi:https://doi.org/10.1002/9780470444894.ch1

Kikuchi, H., Goto, Y., \& Hamaguchi, K. (1986). Reduction of the buried intrachain disulfide bond of the constant fragment of the immunoglobulin light chain: global unfolding under physiological conditions.Biochemistry, 25 (8), 2009-2013. doi:10.1021/bi00356a026 
King, A. C., Woods, M., Liu, W., Lu, Z., Gill, D., \& Krebs, M. R. H. (2011). High-throughput measurement, correlation analysis, and machine-learning predictions for $\mathrm{pH}$ and thermal stabilities of Pfizer-generated antibodies. Protein Science, 20 (9), 1546-1557. doi:10.1002/pro.680

Klein, C., Sustmann, C., Thomas, M., Stubenrauch, K., Croasdale, R., Schanzer, J., . . Schaefer, W. (2012). Progress in overcoming the chain association issue in bispecific heterodimeric IgG antibodies.mAbs, 4 (6), 653-663. doi:10.4161/mabs.21379

Kontermann, R. E., \& Brinkmann, U. (2015). Bispecific antibodies.Drug Discovery Today, 20 (7), 838-847. doi:https://doi.org/10.1016/j.drudis.2015.02.008

Koterba, K. L., Borgschulte, T., \& Laird, M. W. (2012). Thioredoxin 1 is responsible for antibody disulfide reduction in CHO cell culture.Journal of Biotechnology, 157 (1), 261-267. doi:https://doi.org/10.1016/j.jbiotec.2011.11.009

Krylov, S. N., \& Dovichi, N. J. (2000). Capillary Electrophoresis for the Analysis of Biopolymers. Analytical Chemistry, 72 (12), 111-128. doi:10.1021/a1000014c

Kuglstatter, A., Stihle, M., Neumann, C., Müller, C., Schaefer, W., Klein, C., . . Early, D. (2017). Structural differences between glycosylated, disulfide-linked heterodimeric Knob-into-Hole Fc fragment and its homodimeric Knob-Knob and Hole-Hole side products.Protein Engineering, Design and Selection, 30 (9), 649-656. doi:10.1093/protein/gzx041

Lacy, E. R., Baker, M., \& Brigham-Burke, M. (2008). Free sulfhydryl measurement as an indicator of antibody stability. Anal Biochem, 382 (1), 66-68. doi:10.1016/j.ab.2008.07.016

Lakbub, J. C., Clark, D. F., Shah, I. S., Zhu, Z., Su, X., Go, E. P., . . . Desaire, H. (2016). Disulfide bond characterization of endogenous IgG3 monoclonal antibodies using LC-MS: an investigation of IgG3 disulfide-mediated isoforms. Analytical Methods, 8 (31), 6046-6055. doi:10.1039/C6AY01248E

Lakbub, J. C., Shipman, J. T., \& Desaire, H. (2018). Recent mass spectrometry-based techniques and considerations for disulfide bond characterization in proteins. Analytical and Bioanalytical Chemistry, 410 (10), 2467-2484. doi:10.1007/s00216-017-0772-1

Li, W., Prabakaran, P., Chen, W., Zhu, Z., Feng, Y., \& Dimitrov, D. S. (2016). Antibody Aggregation: Insights from Sequence and Structure.Antibodies, 5 (3). doi:10.3390/antib5030019

Li, Y. (2019). A brief introduction of IgG-like bispecific antibody purification: Methods for removing product-related impurities.Protein Expression and Purification, 155 , 112-119. doi:https://doi.org/10.1016/j.pep.2018.11.011

Liu, H., Chumsae, C., Gaza-Bulseco, G., Hurkmans, K., \& Radziejewski, C. H. (2010). Ranking the Susceptibility of Disulfide Bonds in Human IgG1 Antibodies by Reduction, Differential Alkylation, and LC-MS Analysis. Analytical Chemistry, 82 (12), 5219-5226. doi:10.1021/ac100575n

Liu, H., Gaza-Bulseco, G., \& Chumsae, C. (2009). Analysis of reduced monoclonal antibodies using size exclusion chromatography coupled with mass spectrometry. Journal of the American Society for Mass Spectrometry, 20 (12), 2258-2264. doi:10.1016/j.jasms.2009.08.015

Liu, H., Gaza-Bulseco, G., \& Lundell, E. (2008). Assessment of antibody fragmentation by reversedphase liquid chromatography and mass spectrometry. Journal of Chromatography B, 876 (1), 13-23. doi:https://doi.org/10.1016/j.jchromb.2008.10.015

Liu, H., \& May, K. (2012). Disulfide bond structures of IgG molecules.mAbs, 4 (1), 17-23. doi:10.4161/mabs.4.1.18347

Liu, H., Nowak, C., Shao, M., Ponniah, G., \& Neill, A. (2016). Impact of cell culture on recombinant monoclonal antibody product heterogeneity. Biotechnology Progress, 32 (5), 1103-1112. doi:10.1002/btpr.2327 
Liu, H., Ponniah, G., Zhang, H.-M., Nowak, C., Neill, A., Gonzalez-Lopez, N., . . . Andrien, B. (2014). In vitro and in vivo modifications of recombinant and human IgG antibodies. mAbs, 6 (5), 1145-1154. doi:10.4161/mabs.29883

Liu, H. F., Ma, J., Winter, C., \& Bayer, R. (2010). Recovery and purification process development for monoclonal antibody production.mAbs, 2 (5), 480-499. doi:10.4161/mabs.2.5.12645

Magnusson, C. G. M., Bjornstedt, M., \& Holmgren, A. (1997). Human IgG is substrate for the thioredoxin system: Differential cleavage pattern of interchain disulfide bridges in IgG subclasses. Molecular Immunology, 34 (10), 709-717. doi:https://doi.org/10.1016/S0161-5890(97)00092-8

Mamathambika, B. S., \& Bardwell, J. C. (2008). Disulfide-Linked Protein Folding Pathways. Annual Review of Cell and Developmental Biology, 24 (1), 211-235. doi:10.1146/annurev.cellbio.24.110707.175333

Manteca, A., Alonso-Caballero, A., Fertin, M., Poly, S., De Sancho, D., \& Perez-Jimenez, R. (2017). The influence of disulfide bonds on the mechanical stability of proteins is context dependent. Journal of Biological Chemistry, 292 (32), 13374-13380. Retrieved from http://www.jbc.org/content/292/32/13374.abstractN2

Mazor, Y., Oganesyan, V., Yang, C., Hansen, A., Wang, J., Liu, H., . . . Chowdhury, P. S. (2015). Improving target cell specificity using a novel monovalent bispecific IgG design. mAbs, 7 (2), 377-389. doi:10.1080/19420862.2015.1007816

Megson, S. D., Wilson, M., \& MacGregor, S. A. (2002). Multiphase Flow Investigation of a Centrifugal Filter Using Computational Fluid Dynamics and Experiments . https://doi.org/10.1115/PVP2002-1570

Meister, A., \& Anderson, M. E. (1983). GLUTATHIONE. Annual Review of Biochemistry, 52 (1), 711-760. doi:10.1146/annurev.bi.52.070183.003431

Molina-Miras, A., Sanchez-Miron, A., Garcia-Camacho, F., \& Molina-Grima, E. (2018). CFD-aided optimization of a laboratory-scale centrifugation for a shear-sensitive insect cell line. Food and Bioproducts Processing, 107 , 113-120. doi:https://doi.org/10.1016/j.fbp.2017.11.005

Moussa, E. M., Panchal, J. P., Moorthy, B. S., Blum, J. S., Joubert, M. K., Narhi, L. O., \& Topp, E. M. (2016). Immunogenicity of Therapeutic Protein Aggregates. Journal of Pharmaceutical Sciences, 105 (2), 417-430. doi:https://doi.org/10.1016/j.xphs.2015.11.002

Mullard, A. (2011). 2010 FDA drug approvals. Nature Reviews Drug Discovery, 10 (2), 82-85. doi:10.1038/nrd3370

Mullard, A. (2012). 2011 FDA drug approvals. Nature Reviews Drug Discovery, 11 (2), 91-94. doi:10.1038/nrd3657

Mullard, A. (2013). doi:10.1038/nrd3946

2012 FDA drug approvals. Nature Reviews Drug Discovery, 12 (2), 87-90.

Mullard, A. (2014).

2013 FDA drug approvals. Nature Reviews Drug Discovery, 13 (2), 85-89. doi:10.1038/nrd4239

Mullard, A. (2015).

2014 FDA drug approvals. Nature Reviews Drug Discovery, 14 (2), 77-81. doi:10.1038/nrd4545

Mullard, A. (2016). 2015 FDA drug approvals. $\quad$ Nature Reviews Drug Discovery, 15 (2), 73-76. doi:10.1038/nrd.2016.15

Mullard, A. (2017). 2016 FDA drug approvals. Nature Reviews Drug Discovery, 16 (2), 73-76. doi:10.1038/nrd.2017.14

Mullard, A. (2018). 2017 FDA drug approvals. Nature Reviews Drug Discovery, 17 (2), 81-85. doi:10.1038/nrd.2018.4 
Mullard, A. (2019). 2018 FDA drug approvals. $\quad$ Nature Reviews Drug Discovery (18), 85-89. doi:10.1038/d41573-019-00014-x

Mullard, A. (2020). 2019 FDA drug approvals. Nature Reviews Drug Discovery 19 , 79-84. doi:10.1038/d41573-020-00001-7

Mun, M., Khoo, S., Do Minh, A., Dvornicky, J., Trexler-Schmidt, M., Kao, Y.-H., \& Laird, M. W. (2015). Air sparging for prevention of antibody disulfide bond reduction in harvested CHO cell culture fluid. Biotechnology and Bioengineering, 112 (4), 734-742. doi:10.1002/bit.25495

Nelson, P. N., Reynolds, G. M., Waldron, E. E., Ward, E., Giannopoulos, K., \& Murray, P. G. (2000). Demystified... Molecular Pathology, 53 (3), 111. doi:10.1136/mp.53.3.111

Nie, S., Wang, Z., Moscoso-Castro, M., D’Souza, P., Lei, C., Xu, J., \& Gu, J. (2020). Biology drives the discovery of bispecific antibodies as innovative therapeutics. Antibody Therapeutics, 3 (1), 18-62. doi:10.1093/abt/tbaa003

O'Mara, B., Gao, Z.-H., Kuruganti, M., Mallett, R., Nayar, G., Smith, L., . . . Fann, J. (2019). Impact of depth filtration on disulfide bond reduction during downstream processing of monoclonal antibodies from CHO cell cultures. Biotechnology and Bioengineering, 116 (7), 1669-1683. doi:10.1002/bit.26964

Ostergaard, H., Tachibana, C., \& Winther, J. R. (2004). Monitoring disulfide bond formation in the eukaryotic cytosol. Journal of Cell Biology, 166 (3), 337-345. doi:10.1083/jcb.200402120

Patel, B. A., Gospodarek, A., Larkin, M., Kenrick, S. A., Haverick, M. A., Tugcu, N., . . . Richardson, D. D. (2018). Multi-angle light scattering as a process analytical technology measuring real-time molecular weight for downstream process control. $m A b s, 10$ (7), 945-950. doi:10.1080/19420862.2018.1505178

Patel, B. A., Pinto, N. D. S., Gospodarek, A., Kilgore, B., Goswami, K., Napoli, W. N., . . . Richardson, D. D. (2017). On-Line Ion Exchange Liquid Chromatography as a Process Analytical Technology for Monoclonal Antibody Characterization in Continuous Bioprocessing. Analytical Chemistry, 89 (21), 11357-11365. doi:10.1021/acs.analchem.7b02228

Paul, S., Connor, J., Nesspor, T., Haytko, P., Boakye, K., Chiu, M. L., \& Jiang, H. (2016). An efficient process of generating bispecific antibodies via controlled Fab-arm exchange using culture supernatants.Protein Expression and Purification, 121 , 133-140. doi:https://doi.org/10.1016/j.pep.2016.01.014

Preud'homme, J.-L., Petit, I., Barra, A., Morel, J.-C. L. F., \& Lelievre, E. (2000). Structural and functional properties of membrane and secreted IgD. Molecular Immunology, 37 (15), 871-887. doi:https://doi.org/10.1016/S0161-5890(01)00006-2

Pristatsky, P., Cohen, S. L., Krantz, D., Acevedo, J., Ionescu, R., \& Vlasak, J. (2009). Evidence for Trisulfide Bonds in a Recombinant Variant of a Human IgG2 Monoclonal Antibody. Analytical Chemistry, 81 (15), 6148-6155. doi:10.1021/ac9006254

Raju, T. N. K. (1999). The Nobel Chronicles. The Lancet, 354 (9183), 1040. doi:https://doi.org/10.1016/S0140-6736(05)76658-7

Rao, P. E., \& Kroon, D. J. Orthoclone OKT3. Chemical mechanisms and functional effects of degradation of a therapeutic monoclonal antibody. (1078-0467 (Print)).

Ratanji, K. D., Derrick, J. P., Dearman, R. J., \& Kimber, I. (2014). Immunogenicity of therapeutic proteins: Influence of aggregation. Journal of Immunotoxicology, 11 (2), 99-109. doi:10.3109/1547691X.2013.821564

Read, E. K., Park, J. T., Shah, R. B., Riley, B. S., Brorson, K. A., \& Rathore, A. S. (2010). Process analytical technology (PAT) for biopharmaceutical products: Part I. concepts and applications. Biotechnology and Bioengineering, 105 (2), 276-284. doi:10.1002/bit.22528 
Read, E. K., Shah, R. B., Riley, B. S., Park, J. T., Brorson, K. A., \& Rathore, A. S. (2010). Process analytical technology (PAT) for biopharmaceutical products: Part II. Concepts and applications.Biotechnology and Bioengineering, 105 (2), 285-295. doi:10.1002/bit.22529

Ricker, R. D., \& Sandoval, L. A. (1996). Fast, reproducible size-exclusion chromatography of biological macromolecules. Journal of Chromatography A, 743 (1), 43-50. doi:https://doi.org/10.1016/00219673(96)00283-X

Rose, P. (2008). Biopharmaceutical technology: Cell harvesting - getting cultural. Filtration 83 Separation, 45 (8), 29-31. doi:https://doi.org/10.1016/S0015-1882(08)70297-0

Rosenberg, A. S. (2006). Effects of protein aggregates: An immunologic perspective. The AAPS Journal, 8 (3), E501-E507. doi:10.1208/aapsj080359

Rossi, E. A., Goldenberg, D. M., Cardillo, T. M., McBride, W. J., Sharkey, R. M., \& Chang, C.-H. (2006). Stably tethered multifunctional structures of defined composition made by the dock and lock method for use in cancer targeting. Proceedings of the National Academy of Sciences, 103 (18), 6841. doi:10.1073/pnas.0600982103

Runcie, K., Budman, D. R., John, V., \& Seetharamu, N. (2018). Bi-specific and tri-specific antibodies- the next big thing in solid tumor therapeutics. Molecular Medicine, 24 (1), 50. doi:10.1186/s10020-018-0051-4

Sankar, K., Hoi, K. H., Yin, Y., Ramachandran, P., Andersen, N., Hilderbrand, A., . . . Zhang, Q. (2018). Prediction of methionine oxidation risk in monoclonal antibodies using a machine learning method.mAbs, 10 (8), 1281-1290. doi:10.1080/19420862.2018.1518887

Sedykh, S. E., Prinz, V. V., Buneva, V. N., \& Nevinsky, G. A. (2018). Bispecific antibodies: design, therapy, perspectives. Drug design, development and therapy, 12 , 195-208. doi:10.2147/DDDT.S151282

Shukla, A. A., Hubbard, B., Tressel, T., Guhan, S., \& Low, D. (2007). Downstream processing of monoclonal antibodies-Application of platform approaches. Journal of Chromatography B, 848 (1), 28-39. doi:https://doi.org/10.1016/j.jchromb.2006.09.026

Simon, L. L., Pataki, H., Marosi, G., Meemken, F., Hungerbuhler, K., Baiker, A., . . . Chiu, M.-S. (2015). Assessment of Recent Process Analytical Technology (PAT) Trends: A Multiauthor Review. Organic Process Research 83 Development, 19 (1), 3-62. doi:10.1021/op500261y

Swope, N., Chung, W. K., Cao, M., Motabar, D., Liu, D., Ahuja, S., \& Handlogten, M. (2020). Impact of enzymatic reduction on bivalent bispecific antibody fragmentation and loss of product purity upon reoxidation. Biotechnol Bioeng, 117 (4), 1063-1071. doi:10.1002/bit.27264

Tan, Z., Ehamparanathan, V., Ren, T., Tang, P., Hoffman, L., Kuang, J., . . . Liu, S. (2020). On-column disulfide bond formation of monoclonal antibodies during Protein A chromatography eliminates low molecular weight species and rescues reduced antibodies. mAbs, 12 (1), 1829333. doi:10.1080/19420862.2020.1829333

Tang, P., Tan, Z., Ehamparanathan, V., Ren, T., Hoffman, L., Du, C., . . . Liu, S. (2020). Optimization and kinetic modeling of interchain disulfide bond reoxidation of monoclonal antibodies in bioprocesses.mAbs, 12 (1), 1829336. doi:10.1080/19420862.2020.1829336

Trexler-Schmidt, M., Sargis, S., Chiu, J., Sze-Khoo, S., Mun, M., Kao, Y.-H., \& Laird, M. W. (2010). Identification and prevention of antibody disulfide bond reduction during cell culture manufacturing. Biotechnology and Bioengineering, 106 (3), 452-461. doi:10.1002/bit.22699

Trivedi, M. V., Laurence, J. S., \& Siahaan, T. J. (2009a). The role of thiols and disulfides in protein chemical and physical stability. Current protein $\&$ peptide science, 10 (6), 614-625. Retrieved from http://www.ncbi.nlm.nih.gov/pmc/articles/PMC3319691/ 
Trivedi, M. V., Laurence, J. S., \& Siahaan, T. J. (2009b). The role of thiols and disulfides on protein stability. Current protein \& peptide science, 10 (6), 614-625. doi:10.2174/138920309789630534

Tu, B. P., Ho-Schleyer, S. C., Travers, K. J., \& Weissman, J. S. (2000). Biochemical Basis of Oxidative Protein Folding in the Endoplasmic Reticulum. Science, 290 (5496), 1571. doi:10.1126/science.290.5496.1571

Tustian, A. D., Endicott, C., Adams, B., Mattila, J., \& Bak, H. (2016). Development of purification processes for fully human bispecific antibodies based upon modification of protein A binding avidity. $m A b s$, 8 (4), 828-838. doi:10.1080/19420862.2016.1160192

Vaks, L. L.-G., D.; Dror, S.; Shefet-Carasso, L.; Matatov, G.; Nahary, L.; Shapira, S.; Hakim, R.; Alroy, I.; Benhar, I. (2018). Design Principles for Bispecific IgGs, Opportunities and Pitfalls of Artificial Disulfide Bonds. Antibodies 7 (27).

Vazquez-Rey, M., \& Lang, D. A. (2011). Aggregates in monoclonal antibody manufacturing processes. Biotechnology and Bioengineering, 108 (7), 1494-1508. doi:10.1002/bit.23155

Wagner, E., Colas, O., Chenu, S., Goyon, A., Murisier, A., Cianferani, S., . . . Beck, A. (2020). Determination of size variants by CE-SDS for approved therapeutic antibodies: Key implications of subclasses and light chain specificities. Journal of Pharmaceutical and Biomedical Analysis, 184 , 113166. doi:https://doi.org/10.1016/j.jpba.2020.113166

Wang, T., Liu, Y. D., Cai, B., Huang, G., \& Flynn, G. C. (2015). Investigation of antibody disulfide reduction and re-oxidation and impact to biological activities. Journal of Pharmaceutical and Biomedical Analysis, 102 , 519-528. doi:https://doi.org/10.1016/j.jpba.2014.10.023

Wang, X., Kumar, S., \& Singh, S. K. (2011). Disulfide Scrambling in IgG2 Monoclonal Antibodies: Insights from Molecular Dynamics Simulations. Pharmaceutical Research, 28 (12), 3128-3144. doi:10.1007/s11095011-0503-9

Wasalathanthri, D. P., Rehmann, M. S., Song, Y., Gu, Y., Mi, L., Shao, C., . . . Li, Z. J. (2020). Technology outlook for real-time quality attribute and process parameter monitoring in biopharmaceutical development-A review. Biotechnol Bioeng, 117 (10), 3182-3198. doi:10.1002/bit.27461

Wu, L., Seung, E., Xu, L., Rao, E., Lord, D. M., Wei, R. R., . . Nabel, G. J. (2020). Trispecific antibodies enhance the therapeutic efficacy of tumor-directed $\mathrm{T}$ cells through $\mathrm{T}$ cell receptor co-stimulation. Nature Cancer, 1 (1), 86-98. doi:10.1038/s43018-019-0004-z

Xie, H., Chakraborty, A., Ahn, J., Yu, Y. Q., Dakshinamoorthy, D. P., Gilar, M., . . . Mazzeo, J. R. (2010). Rapid comparison of a candidate biosimilar to an innovator monoclonal antibody with advanced liquid chromatography and mass spectrometry technologies. mAbs, 2 (4), 379-394. doi:10.4161/mabs.11986

Xie, P., Niu, H., Chen, X., Zhang, X., Miao, S., Deng, X., . . . Fan, L. (2016). Elucidating the effects of pH shift on IgG1 monoclonal antibody acidic charge variant levels in Chinese hamster ovary cell cultures. Applied Microbiology and Biotechnology, 100 (24), 10343-10353. doi:10.1007/s00253-016-7749-4

Yang, R., Tang, Y., Zhang, B., Lu, X., Liu, A., \& Zhang, Y. T. (2015). High resolution separation of recombinant monoclonal antibodies by size-exclusion ultra-high performance liquid chromatography (SE-UHPLC).Journal of Pharmaceutical and Biomedical Analysis, 109 , 52-61. doi:https://doi.org/10.1016/j.jpba.2015.02.032

Yang, X., Zhang, Y., Wang, F., Wang, L., Richardson, D., Shameem, M., \& Ambrogelly, A. (2015). Analysis and purification of IgG4 bispecific antibodies by a mixed-mode chromatography. Analytical Biochemistry, 484, 173-179. doi:https://doi.org/10.1016/j.ab.2015.06.014

Zhang, Q., \& Flynn, G. C. (2013). Cysteine Racemization on IgG Heavy and Light Chains. Journal of Biological Chemistry, 288 (48), 34325-34335. 
Zhang, T., Zhang, J., Hewitt, D., Tran, B., Gao, X., Qiu, Z. J., . . . Kao, Y.-H. (2012). Identification and Characterization of Buried Unpaired Cysteines in a Recombinant Monoclonal IgG1 Antibody.Analytical Chemistry, 84 (16), 7112-7123. doi:10.1021/ac301426h

Zhang, W., \& Czupryn, M. J. (2002). Free Sulfhydryl in Recombinant Monoclonal Antibodies. Biotechnology Progress, 18 (3), 509-513. doi:10.1021/bp025511z

Zhu, H., Dupureur, C. M., Zhang, X., \& Tsai, M. D. (1995). Phospholipase A2 engineering. The roles of disulfide bonds in structure, conformational stability, and catalytic function. Biochemistry, 34 (46), 15307-15314. doi:10.1021/bi00046a040

Table 1: Reported approaches to prevent disulfide bond reduction and rescue reduced mAb during manufacturing process

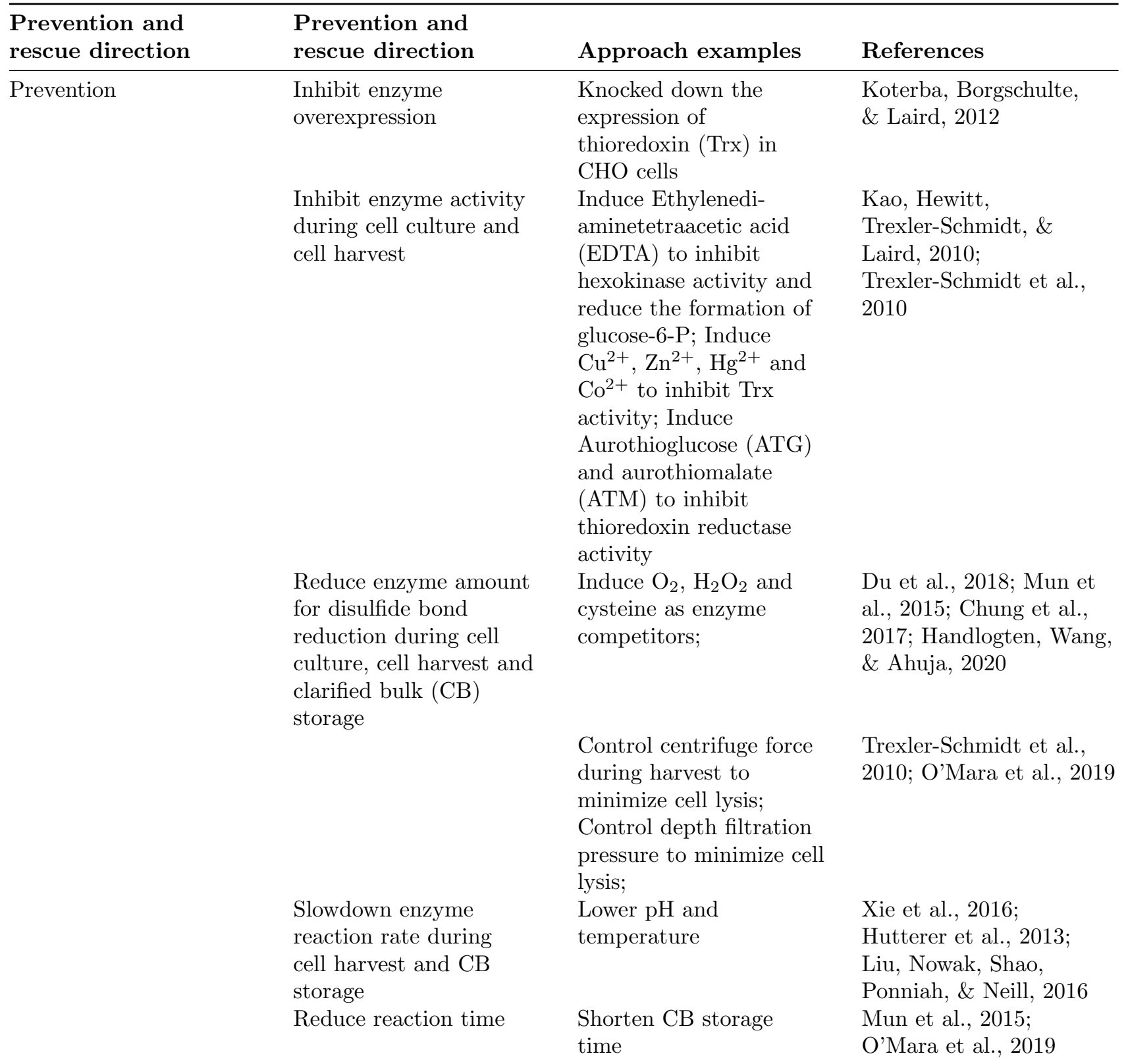




\begin{tabular}{llll}
\hline $\begin{array}{l}\text { Prevention and } \\
\text { rescue direction }\end{array}$ & $\begin{array}{l}\text { Prevention and } \\
\text { rescue direction }\end{array}$ & Approach examples & References \\
\hline Rescue & $\begin{array}{l}\text { Reoxidize reduced } \\
\text { mAb during Protein A } \\
\text { chromatography }\end{array}$ & $\begin{array}{l}\text { Introduce redox wash } \\
\text { to reoxidize reduced } \\
\text { mAb }\end{array}$ & $\begin{array}{l}\text { Tan et al., 2020; Tang } \\
\text { et al., 2020 }\end{array}$ \\
& & & \\
\hline
\end{tabular}

FIGURE 1 Illustrations of disulfide bond structure. (A) Intra-chain disulfide bond connects two betasheets in Ig domain (Li, Prabakaran et al. 2016). (B) Intra-chain and inter-chain disulfide bonds in a IgG monomer; (C) "knob-into-holes (Kih)" IgG-like bispecific antibody (BsAb) stability can be improved by having additional disulfide bonds (red line) formed in the Kih region; (D) Disulfide bond can improve correctly pairing IgG-like BsAb light chain and heavy chain: in one arm, the cysteine residues in $\mathrm{C}_{\mathrm{H}}$ and $\mathrm{C}_{\mathrm{L}}$ that originally formed disulfide were mutated into valine, and introduced an addition disulfide bond (marked as red) during the mutation; the other arm kept unmutated; (E) Dual Affinity Retargeting Molecules (DART), light chain variable region from one antibody is linked to the heavy chain variable region from the other antibody through small peptide (black dash line), and the two variable regions are linked through disulfide bond (red solid line).

FIGURE 2 (A) Protein A chromatography profile from mAb3 purification process (B) AEX (Flow through mode) from mAb1 purification process; (C) CEX (bind and elute mode) from mAb1 purification process. Blue line represented the load sample that had no significant level disulfide bond reduction, red line represented the load sample that had disulfide bond reduction. The tail part for each step were normalized and enlarged for comparison purpose.

FIGURE 3 Qualifications of product quality attributes for $\mathrm{mAb} 1$ and $\mathrm{mAb} 2$ during downstream processing. (A) During the low $\mathrm{pH}$ viral inactivation step, for $\mathrm{mAb} 1$, the HMW\% for intact $\mathrm{mAb}$ pool and reduced $\mathrm{mAb}$ pool increased at similar level $(0.5 \sim 0.6 \%)$; for $\mathrm{mAb}$, the HMW\% decreased more for intact $\mathrm{mAb}$ pool ($1.7 \%)$ than reduced $\mathrm{mAb}$ pool (-0.3\%); (B) For both $\mathrm{mAb1}$ and $\mathrm{mAb2}$, reduced mAb pool purity increased during downstream process, showed the possibilities that reduced mAb can re-oxidize.

FIGURE 4 Stability of antibody samples with varied initial disulfide reduction levels under the conditions of room temperature $\left(25^{\circ} \mathrm{C}\right)$, high temperature $\left(40{ }^{\circ} \mathrm{C}\right)$, and light exposure at $25^{\circ} \mathrm{C}$ for total 14 days. A, Aggregation level as a function of time for all studied conditions; B, Zoom-in profile of aggregation level as a function of time for $25 \mathrm{C}$ and $40 \mathrm{C}$.

FIGURE 5 Different approaches have been applied in mAb manufacturing process to prevent disulfide bond reduction and recover reduced mAb.

FIGURE 6 Comprehensive evaluation of using redox wash system in the platform Protein A chromatography (Tan, Ehamparanathan et al. 2020). The study was performed using three mAb harvest cell cultures according to the design including three arms. The protein A pools from each run was tested for product quality attributes. (A) Comprehensive study: Arm 1, control; Arm 2, combined wash step; (B) Intact mAb impurity; (C) Aggregates (HMW\%).

\section{Hosted file}

Paper Disulfide bond review Figure 15Dec2020.pdf available at https://authorea.com/ users/383816/articles/499647-antibody-disulfide-bond-reduction-and-recovery-during-

biopharmaceutical-process-development-a-review 